\title{
ANALISIS NOMINAL GROUP EXPERIENTIAL PADA STRUKTUR KALIMAT BAHASA INGGRIS: KAJIAN TATA BAHASA FUNGSIONAL
}

\author{
Daliman \\ English Department of UNIKOM \\ chelsea_subang@yahoo.com
}

\begin{abstract}
Abstrak
Artikel berjudul "Analisis Nominal Group Experiential Pada Struktur Kalimat Bahasa Inggris" membahas masalah functional components bentuk Nominal Group. Nominal Group memiliki variasi yang dapat meliputi beberapa bentuk kelas kata yang diklasifikasi kedalam fungsional strukturnya dibanding group lainnya. Tujuan dari artikel ini adalah untuk mendeskripsikan, menjelaskan Nominal Group apa yang terdapat pada data dalam artikel berita bisnis BBC dan memunculkan jenis Experiential Roles apa yang terdapat pada Nominal Group tersebut. Teori Nominal Group digunakan untuk menganalisis data dari Halliday (1984), dan Bloor dan Bloor (2004). Metode yang digunakan di artikel ini adalah metode deskriptif dengan menganalisis dan memaparkan data yang diambil dari artikel berita bisnis BBC. Berdasarkan analisis yang dilakukan, dapat disimpulkan bahwa klasifikasi nominal group yang terdiri dari premodifier dan Head, premodifier tersebut meliputi beberapa unit konstituen seperti: determiner, epithet, deictic, qualifier, numeral, classifier, specifier, dan quantifier, diklasifikasikan ke dalam jenis elemen berbeda sesuai dengan kelas kata yang membentuk premodifier.
\end{abstract}

Kata Kunci: functional grammar, nominal group experiential, fungsional struktur.

\begin{abstract}
This article "Nominal Group Experiential Analysis in English Structures" discusses the issue of functional components in the form Nominal Group. Nominal Group has a variation that can include multiple forms of word classes that are classified into functional structures than any other group. The purpose of this article is to describe, to analyze the Nominal Group what is contained in the data in the BBC business news articles and bring what kind of Experiential Roles contained in the Nominal Group on data. Theory of Nominal Group Experiential is used to analyze the data from Halliday (1984), and Bloor dan Bloor (2004). The method used in this article is descriptive to analyze and to explain the data taken from the $B B C$ business news articles. From the analysis conducted, it can be concluded that the classification of Nominal Group consisting of Premodifier and Head, Premodifier
\end{abstract}


comprise constituent units such as: Determiner, Epithet, Deictic, Qualifier, Numeral, Classifier, Specifiers, and Quantifiers, classified into types of different elements in accordance with the class of words that form of premodifier.

Keywords: functional grammar, nominal group experiential, functional structure

\section{Pendahuluan}

Nominal Group adalah salah satu grup dari beberapa antar grup kata dan struktur dalam bahasa Inggris. Diantaranya Verbal Group, Adverbial Group, Conjunction Group, Preposition Group dan Nominal Group. Namun penulis membatasi hanya akan membahas Nominal Group saja. Karena jenis Nominal Group memiliki jumlah functional components di antara grup lainnya. Artinya fungsional komponen dalam Nominal Group memiliki variasi yang dapat meliputi beberapa bentuk kelas kata yang diklasifikasi ke dalam fungsional strukturnya dibanding dengan grup lain. Sebagaimana yang Gerot dan Wignell kemukakan (1994:141) "A nominal group is a group of words which has a noun (a word which names a person, place or thing) as its head word and includes all additional information related to that noun. As a means of representing experience, the nominal group has a number of functional components. Pernyataan tersebut diatas menjelaskan bahwa Nominal Groups adalah kumpulan kata yang memiliki sebuah kata benda terdiri dari head + modifier. Artinya didalam sebuah kalimat itu ada induk kata, dan kata setelahnya semua informasi tambahan yang berkatian dengan kata benda tersebut. Seperti dalam contoh: chicken, Satu kata benda saja bisa disebut Nominal Groups. Yaitu berupa kata benda chicken. Terminologi kata benda chicken itu sendiri dalam struktur fungsionalnya adalah Thing. Thing ini adalah struktur fungsional jenis Experiential.

Berdasarkan fenomena diatas, penulis menganalisis jenis Nominal Group Experiential dalam struktur bahasa inggris. Artikel ini dianalisis menggunakan satu teori.

\section{Sumber Data}

Dalam penelitian ini, data diambil dari BBC (www.bbc.com) pada beberapa artikel bisnis, Kemudian setelah itu setiap kalimat dicari Nominal Groups Experiential, setelah itu memunculkan apa saja Nominal Groups Experiential yang ada pada data-data tersebut, lalu penulis memilih data yang representative untuk dianalisis.

\section{Metode}

Metode yang digunakan dalam penelitian ini adalah metode deskriptif. Metode Deskriptif itu sendiri yang dikemukakan oleh Sugiyono (2007:14): 
"Metode deskriftif analisis adalah yang digunakan untuk menganalisa data dengan cara mendeskripsikan atau menggambarkan data yang telah terkumpul sebagaimana adanya".

Menurut Sugiyono (2007:14) penulis dapat menyimpulkan bahwa untuk menganalisis data dapat dilakukan melalui menggambarkan fakta dari data.

\section{Kajian Teori}

Nominal Group adalah salah satu grup dari beberapa antar grup kata dan struktur dalam bahasa Inggris yang memiliki functional components yang lebih luas Secara struktur di antara group lainnya. Menurut Thompson (2000:181) "The nominal group is the grammatical unit which has the most variety at this rank of groups and this would allow the widest range of meanings to be expressed", pernyataan di atas menjelaskan bahwa nominal group merupakan sebuah grup yang terbentuk dari noun (place, thing, person) sebagai head. Selain itu, konstituen lain yang meliputi seluruh informasi tambahan yang berhubungan dengan Head yaitu modifier (premodifier \& postmodifier) seperti yang diutarakan oleh Bloor \& Bloor (2004:31) "A nominal group is typically a group with a noun (or pronoun) as its Head, and that noun may be modified, but it does not have to be modified in order to constitute a group in this technical sense". Contoh bentuk nominal group digambarkan seperti "Those two unique cars from Oklahoma City". Contoh tersebut menerangkan bahwa those two unique merupakan premodifier yang ditempatkan sebelum Head yaitu cars sebagai kata inti dari nominal group. Sementara itu, from Oklahoma City berperan sebagai postmodifier dari Head cars.

Dalam clause as representation, struktur nominal group diklasifikasi dengan komponen ideational metafunctions yaitu: logical dan experiential roles. Berikut ini merupakan pemaparan dari ideational metafunctions.

Ideational metafunctions merupakan salah satu jenis komponen metafunctions yang dibutuhkan untuk menjelaskan 2 jenis komponen ideational yaitu: experiential dan logical, di dalam nominal group komponen tersebut mempunyai keterkaitan satu sama lain secara fungsi dan struktur. Seperti contoh: the beautiful girl.

Konstruksi di atas menunjukan struktur nominal group yang terdiri dari strukrtur Head dan modifier. The dan beautiful berperan sebagai premodifier yaitu secara struktur menghubungkan pada girl sebagai Head, dan untuk memperluas konstruksi tersebut secara fungsional. Konstruksi tersebut dapat dilihat dari fungsi lain, yaitu ketika setiap komponen yang terdapat pada konstruksi tersebut diklasifikasikan dengan jenis-jenis elemen yang menggambarkan karakter dan fungsi dalam konstruksi nominal group. Dari keterangan di atas, kedua fungsi tersebut dapat menentukan girl sejenis dengan thing, begitu juga dengan fungsi the dan beautiful sebagai deictic dan epithet di dalam experiential roles. 
Halliday (1985:192) menyebutkan "however, because of the very diverse ways in which phenomena can be subcategorize, group developed their own multivariate constituent structures, with functional configurations such as the Deictic + Numerative + Epithet + Classifier + Thing of the nominal group in English", pernyataan tersebut menunjukan bahwa dalam nominal group, experiential merupakan struktur yang mengacu pada sumber gramatikal secara fungsional. Experiential memiliki beberapa karakteristik secara struktur yaitu elemen di dalamnya memiliki fungsi masing-masing, elemen tersebut diklasifikasi sesuai dengan perbedaan kelas kata dan rangkaian elemennya sesuai dengan struktur. Konstituen di dalamnya melibatkan beberapa jenis elemen yang seluruhnya mengacu pada karakter Head/thing. Elemen tersebut terdapat dalam rangkaian komponen tertentu, dan sebagian besar ditetapkan oleh rangkaian strukturnya. Dalam nominal group, experiential roles terbagi ke dalam 6 jenis elemen yang menjelaskan masing-masing bentuk dan fungsinya. Yaitu:

\section{Deictic}

Arnold (1985:161) menyebutkan "the Deictic element indicates whether or not some specific Head is intended; and if so, which one", pernyataan di atas menerangkan bahwa deictic berfungsi sebagai elemen yang disisipkan sebagai sebuah perwujudan dari determiner dalam nominal group sebelum elemen thing. Seperti dalam contoh nominal group yaitu the wages of sin, yang berfungsi sebagai deictic dalam nominal group tersebut yaitu determiner the dan berperan sebagai 'pointing' atau yang menunjuk pada elemen utama yaitu Thing. Menurut Gerot \& Wignell (1994:141) "There are are the number of deictic functions but all involve degrees of specification", pernyataan tersebut menunjukan bahwa elemen deictic sendiri dapat terbagi kedalam 2 kategori yaitu: specific dan non-specific.

a. Specific deictic menurut Halliday (1985:160) menyebutkan bahwa subset Specific deictics dapat ditetapkan oleh 2 bentuk deictic yang tepat. Salah satunya merupakan bentuk demonstratetively: dengan referensi beberapa bentuk dengan si penutur seperti: this, these, = "near me"; that, those = "not near me". Selain itu, bentuk lain yang merupakan bentuk yang dapat dikaitkan dengan specific deictic yaitu possesive, dengan referensi terhadap orang yang digambarkan oleh sudut pandang si penutur seperti: (my, your, our, his, her, its, their; also Mary's, my father's, dll.). Namun, specific deictic memiliki satu bentuk lain yaitu the. Kata the merupakan bentuk khusus, karena determinative deictic adalah sebuah jenis yang khas. Maksudnya, subset yang dipertanyakan dapat diidentifikasi, informasinya dapat ditemukan dimana pun berada. Semua contoh di atas memiliki fungsi untuk mengidentifikasi subset tertentu yang mengacu pada thing.

b. Berbeda dengan specific deictics, non-specific deictic tidak berperan sebagai elemen yang mengidentifikasi subset terhadap Thing. Thompson (2000: 182) menyebutkan bahwa "non-specific deictics work in a different way: they 
signal that the hearer or reader is not assumed, or does not need, to be familiar with the specific identity of the Head at that point". Pernyataan tersebut menunjukan bahwa non-specific deictic berperan sebagai elemen yang mengukur kuantitas dari Head, seperti: all, some, non, neither, a, an, any, each, every, both . Seperti pada contoh:

There are some dogs on the yard.

Kata yang diberi tanda italic yaitu some berperan sebagai elemen nonspecific deictic yang berperan sebagai penghitung kuantitas dari dog. Di dalam nominal group, non-specific deictic sering diklasifikasikan sebagai second deictic.

\section{Numerative}

Elemen berikutnya yaitu Numerative, kategori numerative mempunyai keterkaitan dengan Deictic dalam konteks yang lebih luas di dalam nominal group. Menurut Halliday (1994:183) "it indicates the number or quantity of the Head, either in exact terms, 'three', 'twenty', or in inexact terms, 'many', 'much'; or it specifies order, 'first', 'fifth", pada pernyataan di atas disimpulkan bahwa Numerative merupakan elemen yang mempunyai konteks dengan simbol dari angka. Seperti pernyataan di atas, komponen numerative sendiri mempunyai beberapa klasifikasi yaitu: quantity atau order, exact atau inexact. Quantifying berperan untuk menentukan exact number, yaitu bentuk cardinal number seperti: third teams, second chances. Selain itu, quantifying dapat juga menetapkan bentuk inexact number seperti: many cars. Komponen yang kedua digolongkan ke dalam ordinatives, yaitu berperan untuk menetapkan salah satu keterangan dalam urutan angka bilangan exact place seperti: the third players atau inexact place seperti: subsequent bus.

\section{Epithet}

Menurut Halliday (1985:163) epithet merupakan elemen yang menunjukan beberapa sifat dari Thing seperti: young, blue, fast. Fungsinya menunjukan sifat objektif dari Thing itu sendiri, atau dapat juga berfungsi sebagai ekspresi dari sifat subjektif si pembicara terhadapnya seperti: splendid, silly, fantastic. Keduanya mempunyai kriteria dan fungsi yang berbeda, seperti contoh yang menunjukan sifat objektif mempunyai fungsi sebagai experiential, sedangkan yang menunjukan sifat subjektif menerangkan sifat si pembicara, fungsinya mewakili elemen interpersonal di dalam nominal group. Kedua perbedaan tersebut didukung oleh pernyataan oleh Gerot \& Wignell (1994:143) "epithet, this indicates some quality of the subset, which may be either 'objective' such as: old, big, small, or it may be an expression of the speaker's attitude such as: loathsome, nasty". 


\section{Classifier}

Halliday (1985:164) menyebutkan "the classifier indicates a particular subclass of the thing in question", pernyataan tersebut menjelaskan bahwa classifier merupakan elemen yang memberikan penjelasan seperti pertanyaan yang menjelaskan apa jenis atau apa macam dari subset thing itu sendiri. Terkadang, classifier dan epithet sulit untuk dibedakan karena karakteristik keduanya mempunyai kesamaan seperti contoh: fast trains, epithet akan mengasumsikan maknanya sebagai kereta api kilat (express train). Selain itu, classifier akan mengasumsikan fast sebagai item pada subclass dari thing yaitu train. Makna kereta tersebut mempunyai makna sebagai kereta kilat. Classifier mempunyai fungsi yang luas, bentuknya dapat mencakup material, scale dan scope, purpose and function, status dan rank, origin of mode of operation. Kurang atau lebih ciri-cirinya, classifier menyajikan tentang klasifikasi dari setiap hal ke dalam sebuah sistem dari kumpulan-kumpulan yang lebih kecil.

\section{Thing}

Bloor \& Bloor (2004:142) menyebutkan "In this sense, Thing may be a material inanimate thing, an animal, a person, a substance or even an abstract concept", teori di atas menjelaskan bahwa Thing adalah kunci utama dari nominal group, yang jenisnya terbentuk dari bentukan kelas kata noun dan secara khas mempunyai kaitan dengan Head. Seperti contoh: a lovely day, yang menjadi item utama yang berkenaan dengan fungsi experiential metafunctionnya adalah day karena terbentuk dari kelas kata noun. Fungsi dari Thing merupakan kelas item yang dituju dalam nominal group, meskipun elemen utama di dalam konstruksi nominal group tidak selalu berbentuk thing.

\section{Qualifier}

Halliday (1985:166) menyebutkan "what of the element which follow the thing? the original example ended with the phrase with pantographs; this is also is part of the nominal group, having a function we shall refer to as Qualifier", pernyataan di atas menjelaskan bahwa di dalam nominal group terdapat elemen yang mengikuti Head yaitu yang disebut Qualifier. Elemennya memiliki perbedaan karena tidak seperti elemen lain yang mendahului Head yang terbentuk dari kata atau kata kompleks, maka fungsi Qualifier dapat juga disebut sebagai postmodifier, embedded (prepositional phrase \& relative clause). Pernyataan tersebut didukung oleh Thompson (2000: 185) mendeskripsikan bahwa qualifier "As for the Postmodifier, it is typically an embedded phrase or clause, it is also part of the nominal group, having a function referred to by linguists as Qualifier", sebagai contoh: the colours of the rainbow, the merupakan premodifier dan colours sendiri merupakan Head yang diikuti oleh of the rainbow sebagai Qualifier. Di dalam nominal group, prepositional phrase adalah sebuah contoh dari 
embedding yang mana satu susunan disisipkan terhadap konstituen yang lainnya. Sama seperti elemen lain, Qualifier mempunyai fungsi sebagai karakter dari thing, tetapi karakter di sini adalah bentuk dari beberapa proses dalam thing secara langsung maupun secara tidak langsung.

\section{Pembahasan}

Ini adalah pemaparan dari Nominal Group Experiential:

\section{Data 1}

China's central bank has cut interest rates four times since November last year in an effort to boost economic activity.

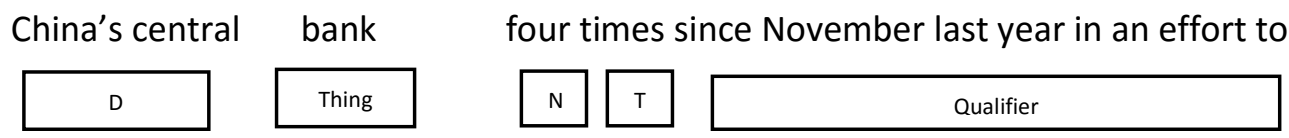

boost economic activity.

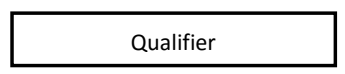

Data 1 di atas menunjukkan China's central merupakan partisipan yang berupa Nominal Group, yang dalam experiential roles sebagai Deictic karena memberitahu pada pembaca China's central yang dimaksud yang mana, spesifikasinya berupa possessive. Bank yang dalam experiential roles sebagai Thing karena kelas kata dari noun. Four yang dalam experiential roles sebagai Numerative karena memberitahu kepada pembaca kuantitas suatu jumlah. Times yang dalam experiential roles sebagai thing, menjelaskan berapa jumlah kuantitas dari suatu jumlah four. Since November last year in an effort to boost economic activity yang dalam experiential roles sebagai Qualifier, karena memodifikasi atau menambahkan informasi tambahan setelah Thing (post-modification) dan Qualifier hampir selalu prepositional phrase.

\section{Data 2}

However, it was still the weakest showing since the global financial crisis, and experts doubt that this level of growth can be sustained.

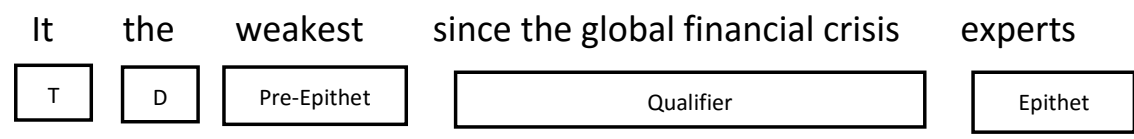

that this level of growth can be sustained. 
Di dalam experiential roles konstituen yang membentuk Nominal Group pada data 2 diatas it sebagai thing merujuk pada kalimat sebelumnya dalam hal ini it merujuk pada Chinese economy grew by $7 \%$ in the April-to-June period, the yang dalam experiential roles sebagai Deictic, menunjukan kepastian letak atau keberadaan suatu benda, spesifikasinya berupa Demonstrative. Weakest yang dalam experiential roles sebagai pre-epithet, menjelaskan seberapa kuat atau lemah kekuatan yang ada dalam hal ini kekuatan yang sangat dibawah batas kekuatan. Since the global financial crisis yang dalam experiential roles sebagai Qualifier, memodifikasi atau menambahkan informasi tambahan atas kemunduran ekonomi Negara China dalam hal finansialnya. Experts yang dalam experiential roles sebagai Epithet, menunjukan kualitas dari thing.

\section{Simpulan}

Berdasarkan penjelasan diatas, dapat disimpulkan bahwa Nominal Group Experiential memiliki 6 jenis elemen yang menjelaskan masing-masing bentuk dan fungsinya: Deictic, Numerative, Epithet, Classifier, Thing dan Qualifier.

\section{Daftar Pustaka}

Arnold, E. 1985. An Introduction to Functional Grammar. London: Routledge.

Bloor, T. and Bloor, Meriel. 2004. The Functional Analysis of English Second Edition. London: Hodder Education.

Halliday, M.A.K 1985. An Introduction to Functional Grammar. London; Baltimore, Md., USA: E. Arnold

Halliday, M.A.K, and C.M.I.M. Matthiessen. 2004. An introduction to functional grammar, 4th Ed. London: Arnold.

Sugiyono. 2007. Metode Penelitian Kuantitatif Kualitatif dan R\&D. Bandung: Alfabeta

Wignell \& Gerot. 1994. Making Sense of Functional Grammar. Australia. 